\title{
La fisionomía del poder en la Castilla del siglo XVIII: poder jurisdiccional y poder concejil en Ávila
}

\section{Castile Crown $18^{\text {th }}$ century territorial power physiognomy: Ávila's jurisdiction's and council's power}

\author{
Rodrigo PousA DiÉGUEZ \\ Investigador Independiente \\ rodrigopousa@gmail.com \\ http://orcid.org/0000-0001-9323-8728
}

Fecha de recepción: 01-04-2020

Fecha de aceptación: 10-05-2020

\section{RESUMEN}

El territorio de los estados modernos europeos se articulaba en su base en torno a dos instituciones básicas jurisdicción y concejos. El presente trabajo pretende ofrecer una visión integral de esta articulación para el reino de Castilla. A través del Catastro de Ensenad y los censos de Aranda y Floridablanca se proporciona una radiografía general de su entramado administrativo, jurisdiccionalización, señorialización y el fenómeno municipal.

Palabras Clave: Jurisdicción, Señorío, Municipio,

Topónimos: Castilla, España,

Período: Edad Moderna

\section{ABSTRACT}

The territory of early modern states territory was articulated around two basic institutions: jurisdiction and council. This work aims to offer an integrated view of the Kingdom of Castile kingdom, focused on the province of Avila, to observe internal differences and compare Castile with the other kingdoms. The Ensenada land registry and Aranda's and Floridablanca's censuses provide a general picture of their administrative framework, jurisdictions, manors and the municipal phenomenon.

Key words: Jurisdiction, manor, municipality,

Toponyms: Castile, Spain,

Period: Early Modern Age 


\section{INTRODUCCIÓN}

La administración del territorio se organizó en los estados de Europa occidental en torno a dos instituciones o formas de poder estrechamente vinculadas la una a la otra: la jurisdicción y el concejo. El presente trabajo pretende ofrecer una visión global de la administración local del Antiguo Régimen, como resultado de la acción y pugna de ambos poderes sobre el territorio. El marco territorial será el del reino de Castilla concentrándonos en la provincia de Ávila. Los primeros intentos de obtener una infografía general se remontan al propio siglo $\mathrm{XVIII}^{1}$, y hasta ahora han cristalizado en varios trabajos regionales (Anes, 1989; Río, 1990; Armas, Ibáñez y Gómez, 1996; Lemeunier, 1998), pero aún no disponemos de una valoración general para el conjunto de la Corona, ni de jurisdicciones, ni de concejos. Esta incógnita perdura también en otros estados europeos, en Francia han cifrado los juzgados entre 30.000 y 80.000 (Mauclair, 2001: 138), y lo mismo sucede en Inglaterra debido a la exención de la common law peas tanto de los núcleos urbanos (Patterson, 1999: 138), como de las jurisdicciones eclesiásticas y señoriales (Montgomery, 2004: 155-169 y Outwite, 2007).

La tarea se antoja hoy más abarcable gracias a la digitalización de una fuente única para este fin: el Catastro de Ensenada. Para evitar vacíos y calibrar las dimensiones de cada entidad territorial los datos del Catastro se han cruzado con los de los Censos de Aranda ${ }^{2}$ y Floridablanca ${ }^{3}$. Aun así, el volumen de jurisdicciones y concejos obliga a acometerla por entidades, se ha elegido el marco de los antiguos reinos históricos, como primer eje vertebrador, y el provincial como segundo (Garrigós, 1982). El Catastro permite, a través de las Respuestas Generales, conocer además de la titularidad de la jurisdicción de cada población, quiénes eran los oficiales de justicia y regimiento al cargo - aunque la cifra de estos últimos no sea fiable- y en algunos casos a quienes tocaba su nombramiento; proporcionando una visión de conjunto del mapa jurisdiccional abulense y los concejos rurales y urbanos enmarcados en él, a través de las comparecencias como de las preguntas 2,28 y 32. Y es la única fuente que proporciona tales datos para todo el espacio de la Corona -con excepción de Vizcaya y las Canarias- (Camarero, 2002); no pudiendo emplearse el propio vecindario por los defectos que presenta (Camarero, Domínguez y Campos, 1991).

\section{LAS JURISDICCIONES}

Una jurisdicción es un espacio sobre el que un propietario tiene el derecho a administrar justicia y con él toda una serie de prerrogativas, en la Edad Moderna, subordinadas a dicha potestad. El derecho a impartir justicia era en origen un derecho privativo del monarca así lo manifiestan El Fuero de Castilla y Las Partidas. Sin embargo, la enajenación de esta jurisdicción fue una constante, tanto por dádiva de los propios monarcas como por la enajenación que de ella hicieron distintos agentes. Así, nobles, monasterios y concejos acapararon el derecho a administrar justicia sobre sus vasallos.

1 Nomenclátor o diccionario de las ciudades, villas, lugares, aldeas, granjas, cotos redondos, cortijos y despoblados de España y sus islas adyacentes: con expresión de la provincia, partido y término a que pertenecen y la clase de justicias que hay en ellas, Madrid, Imprenta Real, 1779.

2 Presenta las siguientes carencias: Almendral, Buenaventura, Cebolla, Benitos, Bohonal, Bravos, Caleruela, Herreruela, Hoyo Quesero, Martilherrero, Pasarilla, Ralegios, San Bartolomé de Corneja, Torralba, Solo Hoyo Quesero revestían cierta entidad. Y los datos de Cebolla pueden considerarse incluidos en Trabancos. Otros deben su ausencia a su despoblamiento: caso de Pasarilla, Raliegos y Torralba. Censo de Aranda (ed. 2016).

3 Almarza, Botalhorno, Casas de Chicapierna, Cebolla, Codorniz, Grajos, Grandes, Tejados Congosto y Casas del Puerto, Guareña y Villadey. Algunas carencias se explican por la despoblación de los núcleos: caso de Botalhorno, Pasarilla. Los datos de Guareña podrían estar integrados con los de Muñez, como los de Pascual Grande en Crespos, Cebolla en Trabancos, Grajos en San Martín y Rinconada en Muñico. Censo de Floridablanca (ed. 1999). 
Jurídicamente, la jurisdicción hispánica se desglosaba en los siguientes competencias y grados: la jurisdicción alta y baja, que permitían conocer causas en primera instancia y en grado de apelación; la jurisdicción civil y criminal, otorgaba el conocimiento de ambos tipos de causa; mientras que, el mero y el misto imperio representaban la capacidad coercitiva y punitiva: el misto permitía punir los delitos leves y el mero los graves. En Francia, cuya organización jurídica también bebe del lus Commune, existió un tercer grado la moyanne"4.

Fue la dotación de estas capacidades la que erigió a los oficiales de justicia en la principal autoridad territorial, la potestad coercitiva los convirtió en un eslabón clave para hacer cumplir las órdenes de la superioridad (fiscales, militares, etc.), en la medida en que los viejos oficiales medievales, tenentes y merinos iban desapareciendo o perdiendo y no se designaron oficiales específicos a cada fin —como por ejemplo la creación de los subdelegados de marina en el XVIII, que sustrajo competencias a los jueces ordinarios costeros-.

La división del territorio en jurisdicciones estuvo determinada por varios factores: la propia voluntad de la Corona para crear demarcaciones territoriales separadas —ejemplo de ello son las merindades en el norte o las comunidades de villa y tierra en la Extremadura castellana-, la encomienda y donación de entidades territoriales más pequeñas como fueron las tenencias y honores (García, 1970; Álvarez, 1993; García, 1985), la voluntad de los señores a la hora de organizar sus señoríos, o de crearlos ex nihilo designando sus propios oficiales de justicia (Pousa, 2018); y la voluntad de las comunidades y agentes concejiles cuya pugna por el autogobierno los llevó a obtener el derecho a elegir a los oficiales de justicia - esto sucedió en el mundo urbano- desgajando la jurisdicción de villas y ciudades de la jurisdicción general de los señores ${ }^{5}$. La naturaleza de los orígenes de estas jurisdicciones ha sido un tema de interés tradicional en la historiografía hispánica que ha puesto de manifiesto su complejidad, no solo por el extravío documental sino por la arbitrariedad de algunos privilegios sobre los que los señores basaron su derecho a impartir justicia (Moxó, 1964 y Pousa, 2018), debido al cambio en el ordenamiento jurídico, pues hasta la baja Edad Media los conceptos de mero misto imperio tuvieron una presencia escasa en las donaciones (Grasotti, 1983). Otros casos, por el contrario, presentan menos dudas, tanto casos de donación como de enajenación (Guilarte,1987).

La señorialización jurisdiccional fue un rasgo común a todos los estados europeos occidentales. La consecuente compartimentación jurisdiccional se ha calificado en Francia como juridification o incluso imbroglio (Crubaugh 2001; Le Page y Loiseau, 2019).

\subsection{El proceso de jurisdiccionalización y señorialización abulense}

El proceso de jurisdiccionalización de Ávila comienza en la Edad Media, y su primera fase arranca con la reordenación del territorio en comunidades de villa y tierra Ávila y Arévalo-, por un lado, y su entrega particulares e instituciones, por otro para su repoblación. Entre las donaciones más antiguas que darían lugar a señoríos jurisdiccionales se encuentran las de Alfonso VI al obispo de Ávila, en 1142 (Barrios, 1973: 99-100). En este caso los dominios episcopales han sido identificados con Aldeanueva y Bonilla de la Sierra, por cuanto Honorio III confirma su posesión en 1224 (Barrios, 1981 4-5).

A esta fase de señorialización corresponden también los señoríos de Cardiel y Navamorcuende segregados del realengo abulense (Moreno, 1992: 80). El documento de donación manifiesta el mandato y finalidad de la donación "poblar de quienquier e a

4 P. Brillon (1727), Dictionnaire des arrêts ou jurisprudence universelle des parlemens de France et autres tribunaux, Paris, 968.

5 Ejemplos de ello los encontramos en Santiago, Zaragoza, etc. 
qualquier fuero que vos querades, e aquellos que poblaren que sean vuestros vasallos"6. Estas donaciones son las que plantean más dudas en torno su jurisdiccionalidad, cuestión planteada por Hilda Grasotti (1967: 134-135), en comparación con otro privilegio cercano en lo temporal y lo territorial el de San Adrián concedido al mismo linaje.

Otros señoríos cuyos orígenes se remontan al siglo XIII son los de Villatoro y Villanueva de Gómez. Aparecen en esta centuria bajo el señorío del obispo de Ávila, don Sancho, y el obispo de Sigüenza, Gonzalo Gómez, respectivamente —don Sancho era del mismo linaje que los señores de Cardiel y Navamorcuende-, y también vinculado a la actividad repobladora. En este caso su traspaso de unos titulares a otros por compraventa dificulta legitimar o no la jurisdiccionalización de estos dominios (Moxó, 1981: 423-429; Moreno, 1992: 93; Martínez, 1983: 605).

Otros dos entes territoriales ya configurados en época de Alfonso VI serían Oropesa y Valdecorneja-Piedrahita. En este caso se trata de dos señoríos realengos, aquellos territorios que los monarcas concedían a miembros de la familia real. Si bien ello les permitió adquirir en origen una entidad territorial separada, facilitando su señorialización posterior, a diferencia de otros señoríos queda claro que se trataba más de una dotación que de una donación perpetua.

Este punto plantea otro debate en torno a la perpetuidad de las donaciones reales, que ya se ha planteado para otros territorios, por cuanto las confirmaciones de reinado en reinado se antojaban necesarias ${ }^{7}$, y abundan también testimonios de los monarcas disponiendo libremente de tierras donadas previamente, requisándolos y entregándolos a nuevos titulares (Franco, 2012: 13-50; Suárez, 1966). ¿Dependió la permanencia de los territorios de las relaciones del monarca con los señores y de su capacidad para despojarlos? ¿o se aplicó el principio de posesión inmemorial empleando el despojo solo como una desamortización forzosa? Fuere como fuere de iure, en la práctica, el señorío de Oropesa y Valdecorneja fue temporal, de Juan Núñez de Lara retornan a realengo con Pedro I (Moreno, 1992: 108).

A Alfonso X se atribuye la señorialización de Velada, llamada antes Atayuela, en 1271 entregada a su escribano, que después la ciudad de Ávila entregaría a su hermano, juez por el rey en la ciudad (Franco, 1990: 34). Ello manifiesta un comportamiento de la capital de la tierra, como sucedía en Segovia, en este periodo, muy superior al de mero centro administrativo, donde el concejo no disponía de autoridad solo sobre sí mismo, sino que su dominio se extendía sobre toda la comunidad, causa que justificaría el germen de sus propios concejos rurales. Otra muestra de este poder es la concesión por la ciudad del territorio de San Adrián en 1283 a Blas Blázquez, juez real (Monsalvo, 1998: 316).

La segregación de Villafranca de la Sierra —Villafranca de Corneja — de la tierra de Ávila, hecha en 1256, también se debe a Alfonso X (Reviejo, 2013: 318): "pora sí y pora quantos del vienieren que lo aian libre y quito, pora dar, pora vender, pora enagenar, pora poblar". Y, sin embargo, su sucesor necesitará una carta de confirmación (Luis, 2013: 127-28).

Pero fue la dinastía Trastámara la responsable de las mayores enajenaciones (Grasotti, 1983; Valdeón, 1968). A Enrique II se debe la señorialización definitiva de Oropesa y Valdecorneja, en 1366 (Franco, 1985: 299-314) y el cambio de señorío de Navas, Villafranca de la Sierra y Navalperal (Martín, 1997; Franco, 2007); Navas, Navalperal y Val de Maqueda

6 Moxó atribuye a estos textos el empleo de figuras arcaicas el traspaso únicamente de solariego, sin embargo, las prerrogativas colonizadoras exceden el ámbito poblacional al permitirle dar fuero. (Moxó, 1973: 43).

7 Véanse las confirmaciones de Villafranca de la Sierra de 1260 y 1313, la de Valdecorneja a Núñez de Lara, entre otras. Reviejo, 2013: 313; Tellería, 2001: 227-232. 
serán entregados a Gonzalo González Dávila en 1372 (Barrios, 1983: 144; Moreno, 1992: 114), cuyo señorío se vería incrementado según Franco Silva por la usurpación de términos adyacentes (Monsalvo, 1998: 301).

Pero las principales señorializaciones se deben a Enrique III: Adrada, Arenas Candeleda, Castillo de Bayuela, Puebla de Santiago de Arañuelo Colmenar de Ferrerías y Candeleda - cuyos privilegios van acompañados de iniciativas repobladoras- (Mitre, 1968: 37-42). En 1393, Enrique III donaría Cespedosa y Puentecongosto (Mitre, 1968: 110111); y Candeleda a Ruy López Dávalos. Botalhorno parece proceder de la donación de Enrique III (Martínez, 2002: 197-206).

Con Juan II y Enrique IV se producen varios cambios de titularidad por despojo y reconcesión: Candeleda es confiscada en 1422 y donada a Pedro López Estúñiga (Moreno, 1992: 113 y Moxó 1973: 95-96); Adrada y Colmenar de las Ferrerías —Mombeltrán— serán entregadas en 1465 a Beltrán de la Cueva; mientras que en el caso de Arenas y Castillo de Bayuelas permanecieron en manos de doña Juana Pimentel y con su matrimonio pasaron a la casa de Saldaña (Moreno, 1992: 112). Las donaciones enriqueñas a Beltrán de la Cueva no dieron como fruto un único estado señorial, sino que este las repartió y constituyó un segundo mayorazgo para su hijo Antonio Cueva Mendoza, con La Adrada como eje, para el que Felipe II creó el consiguiente marquesado en 1570 (Gonzalo, 1994: 177-192).

A la dinastía Trastámara se debe la constitución del señorío de Mancera, en el siglo $X V$, cuando se documenta a su primer señor el IV hijo del I duque de Alba (Monsalvo, 1998: 304); Olmedilla con Enrique IV, y de Serranos Torre y Pascualcobo concedidos al obispo Lope Barrientos (Martínez, 1994), por Juan II (Gómez, 2000: 80-81). Este mismo rey confirmaría la fundación del mayorazgo en torno a Collado Contreras (Guio y Guio, 2007: 44). Igual de tardía es la señorialización de Fuentes del Año y Canales figuran, cuyo primer señor ubicamos en el siglo XVI, de la oligarquía local de Arévalo (Montalvo, 1928: 32 y 282; Ávila, 2003: 100).

Las desmembraciones eclesiásticas afectaron a pocas poblaciones y no dieron origen a nuevas jurisdicciones (Gil, 1986). Felipe II vendería San Bartolomé de Corneja y Vadillo de la Sierra, del señorío arzobispal, y Cisla y Flores de Ávila de origen desconocido por no encontrarse en las relaciones de bienes desmembrados (Salazar, 1688: 65).

Sin embargo, la venta de despoblados de Felipe III y Felipe IV de diversos lugares de la tierra de Ávila — no sin oposición de esta— sí multiplicaron la división del territorio dando origen a las jurisdicciones de Almarza, Pancaliente, Pasarilla del Berrocal, Vadillo de la Nava o El Guijo. Almarza y Pasarilla se integraban en los estados del Marqués de Almarza y el marqués de Campollano respectivamente, ambos títulos adquiridos a Carlos II (Carriazo, 2013). Pero sería Felipe IV el que incrementaría en 19 las jurisdicciones abulenses durante su reinado. Este monarca vendería Adanero, Bercimuelle, Cardeñosa, Herradón, Fontiveros, Mancera de Arriba, Navalperal, Pozanco, San Bartolomé de Pinares, Santa Cruz de Pinares, Santo Domingo de Posadas, Tiemblo, Vega de Santa María y Vita. Los compradores de Cardeñosa, Mancera, Fontiveros, obtendrían después sus respectivos títulos de marquesado, y el de Adanero su condado. Los compradores de Bercimuelle y Vita siguieron la misma estrategia, aunque los marquesados hicieran referencia a otras propiedades. Los marqueses de Navamorcuende ampliaron sus dominios comprando Almendral y Buenaventura; los duques de Peñaranda con Bóveda de Río Almar y Cantaracillo y los señores Adrada, ampliaron sus dominios con la compra de Sotillos, Iglesuela y Piedralavés (Lorenzo e Izquierdo, 2001). En el caso del Guijo consiguió tornó a la Corona, pero le sirvió para erigirse en villa y desgajarse de la tierra de Ávila. 
También intentaron la venta de muchos otros sin éxito: Blasco Jimeno, Cantiveros, Duruelo, Gallegos de Sobrinos, Gamonal, Lomoviejo, Mirueña, Sobrinos, Ojos Albos y Barraco, Algunos concejos consiguieron adquirir la jurisdicción sobre sí: Mingorría, Vadillo Sierra y el Guijo, y probablemente Diego Álvaro. El Tiemblo intentó ganar la puja por su jurisdicción, pero fracasó, y otros lugares adquiridos por señores tantearon su recompra con el nuevo señor, caso de Almendral y Buenaventura, aunque sin éxito, sí lo tuvo Diego Martínez (Lorenzo e Izquiedo, 2001: 216-219).

\subsection{Jurisdiccionalización y señorialización en cifras}

En general el reino de Castilla presenta una media de jurisdiccionalización media, frente a Galicia. Ávila como el resto de la Extremadura castellana presenta uno de los índices de compartimentación jurisdiccional más bajos, debido a la pervivencia de extensas jurisdicciones realengas, como Segovia, Sepúlveda, Arévalo y Ávila (Monsalvo, 1990).

Tabla 1. Jurisdicciones castellanas por provincias, 1768

\begin{tabular}{|c|c|c|c|c|c|c|c|c|}
\cline { 2 - 8 } \multicolumn{1}{c|}{} & Segovia & Ávila & Palencia & Vallad. & Soria & Burgos & Toro & Total \\
\hline Jurisdicción & 95 & 69 & 120 & 98 & 103 & 635 & 73 & 1.193 \\
\hline Habitantes & 157.830 & 91.243 & 95.914 & 65.427 & 65.212 & 399.208 & 44.981 & 919.815 \\
\hline Media & 1.661 & 1.322 & 799 & 667 & 633 & 628 & 616 & 771 \\
\hline
\end{tabular}

En un análisis por provincias, Ávila presenta un grado de señorialización medio alto, más del $50 \%$ de sus habitantes estaban en el siglo XVIII bajo jurisdicción señorial; la media castellana es del $53 \%$, muy alejada de la gallega (Eiras, 1989). 
Tabla 2. Vasallos del reino de Castilla en $1768^{8}$

\begin{tabular}{|c|c|c|c|c|c|c|c|}
\hline \multicolumn{8}{|c|}{$\%$} \\
\hline & Ávila & Burgos & Palencia & Segovia & Soria & Toro & Valladolid \\
\hline Real & $47 ’ 56$ & $54 ' 21$ & 26 '28 & 44 '30 & $67 ' 66$ & 81'24 & 77’38 \\
\hline Particular & $47 ' 21$ & $40 ’ 92$ & 69'95 & $54 ' 54$ & $21^{\prime} 64$ & $15^{\prime} 88$ & 19’06 \\
\hline $\begin{array}{c}\text { Ec. } \\
\text { Regular }\end{array}$ & 0’09 & 2'71 & $2 ’ 05$ & - & $2 ’ 55$ & $1 ’ 46$ & $3 ' 26$ \\
\hline $\begin{array}{c}\text { Ec. } \\
\text { Secular }\end{array}$ & 2'27 & 0'46 & 1'08 & 1'15 & 2'81 & $0 ’ 56$ & 0’30 \\
\hline Ord. Mil. & - & - & $0 ’ 57$ & - & - & 0’85 & - \\
\hline Concejil & 2'49 & $0 ’ 50$ & $0 ’ 07$ & - & 5'35 & 1'48 & - \\
\hline Hospitales & - & 0'23 & - & - & - & - & - \\
\hline Consejos & 0'38 & - & - & - & - & - & - \\
\hline \multicolumn{8}{|c|}{ Habitantes } \\
\hline & Ávila & Burgos & Palencia & Segovia & Soria & Toro & Valladolid \\
\hline Real & 43.391 & 216.424 & 25.205 & 69.921 & 44.123 & 36.543 & 50.630 \\
\hline Particular & 43.081 & 163.340 & 67.092 & 86.092 & 14.112 & 7.145 & 12.470 \\
\hline $\begin{array}{c}\text { Ec. } \\
\text { Regular }\end{array}$ & 78 & 10.801 & 1.967 & - & 1.661 & 656 & 2.132 \\
\hline $\begin{array}{c}\text { Ec. } \\
\text { Secular }\end{array}$ & 2.075 & 1.840 & 1.036 & 1.817 & 1.830 & 254 & 195 \\
\hline Ord. Mil. & - & - & 550 & - & - & 383 & - \\
\hline Concejil & 2.271 & 2.000 & 64 & - & 3.486 & 664 & - \\
\hline Hospitales & - & 916 & - & - & - & - & - \\
\hline Consejos & 347 & - & - & - & - & - & - \\
\hline Todos & 91.243 & 399.208 & 95.914 & 157.830 & 65.212 & 44.981 & 65.427 \\
\hline
\end{tabular}

8 En Valladolid solo se incluyen los datos de la parte castellana; las cifras de Soria no deben considerarse por las deficiencias del C. de Aranda (Pousa, 2020). 
La jurisdicción realenga más importante era la de Ávila, que concentraba al $30 \%$ de la población de su provincia, con 28.075, que, aunque no alcanzaba las dimensiones de Segovia, 46,661 vasallos, y Soria, con 39.700, superaba tanto a Valladolid, con 22.771, como a Burgos, con 14.733, u a otras de gran entidad como Trasmiera, con 17.575.

Tabla 3. Jurisdicciones realengas

\begin{tabular}{|c|c|c|c|c|}
\cline { 2 - 5 } \multicolumn{1}{c|}{} & \multicolumn{2}{c|}{1769} & \multicolumn{2}{c|}{1787} \\
\cline { 2 - 5 } & Hab. & $\%$ & Hab. & $\%$ \\
\hline Ávila & 27.402 & 30 '0 & 31.099 & 29'64 \\
\hline Arévalo & 12.252 & $13^{\prime} 4$ & 13.726 & 13 '08 \\
\hline Madrid Altas & 1.510 & 1 1'65 & 1.682 & 1'60 \\
\hline Cebreros & 1.243 & 1 '36 & 1.753 & 1'67 \\
\hline Armenteros & 411 & 0 0'45 & 556 & 0'53 \\
\hline Riocabado & 219 & 0 0'24 & 287 & 0'27 \\
\hline Salvadiós & 196 & 0'21 & 236 & 0'22 \\
\hline San Esteban & 158 & 0'17 & 156 & 0'15 \\
\hline Total & 43.391 & 47 '56 & 51.871 & 49'43 \\
\hline
\end{tabular}

El principal señorío será el del ducado de Albuquerque, las donaciones del linaje Trastámara lo habían convertido en uno de los principales señores de vasallos desde el siglo XV (Franco, 2015: 83-110), con más de 22.900 vasallos el estado de la casa de Albuquerque competía con casas como Frías, Villena o el Infantado y estados episcopales como el de Santiago. En 1757 los estados de la casa aumentaban con la agregación del condado de Siruela con 2.773 vasallos en Cervera de Pisuerga (Palencia), 905 en Castrejón (Toro) y en Burgos 8.501 repartidos en 23 villas. 
Tabla 4. Jurisdicciones de señorío

\begin{tabular}{|c|c|c|c|c|}
\hline \multirow[b]{2}{*}{ Duque de Albuquerque } & \multicolumn{2}{|c|}{1769} & \multicolumn{2}{|c|}{1787} \\
\hline & 7.170 & $7 ' 86$ & 7.933 & $7 ’ 56$ \\
\hline Conde de Oropesa & 6.913 & $7 ' 57$ & 7.447 & $7 ' 10$ \\
\hline Duque de Peñaranda & 5.838 & $66^{\prime} 40$ & 6.593 & $6 ' 28$ \\
\hline Marqués de Adrada & 4.693 & $5^{\prime} 14$ & 4.593 & 4,38 \\
\hline Marqués de Las Navas & 3.830 & 4'20 & 4.187 & 3'99 \\
\hline Marqués de Navamorcuende & $1.529^{*}$ & $1^{\prime} 67$ & 2.295 & 2'19 \\
\hline Marqués de Astorga & 2.109 & 2'31 & 2.292 & 2'18 \\
\hline Obispo de Ávila & 2.075 & $2 ' 27$ & 2.450 & 2,33 \\
\hline Duque de Alba & 1.742 & $1 ' 91$ & 1.728 & $1 ' 65$ \\
\hline Marqués de Fuente El Sol & 958 & $1 ' 05$ & 1.460 & 1'39 \\
\hline Marqués de Malpica & 939 & $1 ' 02$ & 1.228 & 1'17 \\
\hline Conde de Adanero & 805 & 0 0'88 & 790 & 0,75 \\
\hline Marqués de Villasierra & 723 & $00^{\prime} 79$ & 792 & 0,75 \\
\hline Marqués de Almarza/Flores & 678 & 0774 & 626 & 0,60 \\
\hline Marqués de Cardeñosa & 559 & 0,61 & 759 & 0 '72 \\
\hline Marqués de Almodóvar & 503 & 0,55 & 638 & 0,60 \\
\hline Francisco Tapia & 475 & 0,52 & 631 & 0,60 \\
\hline Marqués de Fontiveros & 415 & 0,45 & 555 & 0,53 \\
\hline Conde de Amayuelas & $306^{*}$ & 0,34 & 468 & 0,45 \\
\hline Conde de Polentinos & 408 & 0,45 & 406 & 0,39 \\
\hline Francisco Godiñez & 379 & 0 '42 & 381 & $0 ’ 36$ \\
\hline Juan Dávila & 370 & 0,41 & 387 & 0,37 \\
\hline Consejo de Cruzada & 347 & 0 0'38 & 469 & $0 ’ 45$ \\
\hline Marqués de Loriana & 319 & 0,35 & 317 & 0,30 \\
\hline José Ucedo & 305 & 0,33 & 288 & 0,27 \\
\hline Marqués de Tejada & 271 & 0,30 & 338 & 0,32 \\
\hline María Suárez Lugo (Cáceres) & 190 & 0 '21 & 212 & 0,20 \\
\hline Julio Rascón (Salamanca) & 130 & 0 '14 & 143 & 0,14 \\
\hline Félix Basanta & 127 & 0 '14 & 144 & 0,14 \\
\hline Santa Clara & 78 & 0 09 & 80 & 0,07 \\
\hline Conde de Ibangordo & 50 & 0,05 & 53 & 0,05 \\
\hline Total & 45.234 & $499^{\prime} 57$ & 50.683 & $48^{\prime} 30$ \\
\hline
\end{tabular}


En segundo lugar, el estado condal de Oropesa, en manos de los Álvarez de Toledo, con los estados de Jarandilla y Frechilla (Fernández, 1977: 9-56), Alcaudete, Deleitosa y Villar de Grajanejos. En 1746 se le unen el marquesado de Aguilar —con 6.954 vasallos en 1769- y el de San Esteban -4.018-, pero en 1768 los estados se separan de nuevo, y Oropesa pasa a manos del $\mathrm{X}$ duque de Huéscar, duque de Montoro y conde-duque de Olivares; y a su muerte en 1770 a la casa ducal de Alba a la que pertenecen en 1787, junto con otros 20 estados más (Calderón y Alonso, 1990: 557-567; Abad, 1995: 527-550; Corada 2015: 61-95; Palencia, 1995: 787-794).

El tercer señor más importante era el duque de Peñaranda, conde de Miranda del Castañar (Soler, 2009; Álvarez, 1972; Polo, 2012: 763-781). Los estados de este señor tuvieron menos alcance que los demás y sus posesiones en otras provincias apenas sumaban en 1768: 10.273 en Segovia, 830 vasallos en Soria y 871 en Toro.

Los estados del conde de Montijo se estructuraban en torno a la Extremadura Castellana con 4.693 en Ávila y 6.069 en Segovia, en 1768.

El marqués de Astorga contaba pocos vasallos en Ávila, frente a otros estados, 12.869 tenía en León; 1.796 de los condados de Monteagudo y Almazán (Soria); 2.182 el de Leganés (Toledo); 1.022 el condado de Velada-San Román; 30.104 los estados de Baena, Cabra e Iznajar (Córdoba); 714 del marquesado de Monzón (Palencia); y 13.342 el ducado de Sanlúcar y el condado de Villamanrique (Sevilla), entre otros.

El señorío eclesiástico en Ávila tenía un escaso peso, solo la mitra y la orden de Santa Clara poseían dominios jurisdiccionales. El señorío episcopal de Ávila contaba con unos 2.025 vasallos, cifra moderada frente al arzobispo de Santiago, pero por encima de muchos otros como el obispo de Osma, Segovia o Sevilla y similar al de León, que como él no pudieron erigirse en señores de sus respetivas ciudades.

Las desmembraciones de señoríos eclesiásticos filipinas tuvieron un escaso impacto en la región, donde el señorío eclesiástico se reducía a las propiedades episcopales. Solo San Bartolomé de Corneja y Vadillo de la Sierra serían enajenadas (Faya, 1998). Los beneficiarios fueron los que mostraban los tanteos y San Bartolomé de Corneja pasaría al señorío de los Pacheco Espinosa, que obtendrían de Carlos II el condado de Ibangrande (Francisco, 1999: 65 y 98) y Vadillo de la Sierra era comprada por los propios vecinos (Faya, 1998).

Tabla 5. Jurisdicciones concejiles

\begin{tabular}{|c|c|c|c|c|}
\cline { 2 - 5 } \multicolumn{1}{c|}{} & \multicolumn{2}{c|}{1769} & \multicolumn{2}{c|}{1787} \\
\cline { 2 - 5 } & Hab. & $\%$ & Hab. & $\%$ \\
\hline Mingorría & 1.009 & 1'10 & 975 & 0'93 \\
\hline Vadillo & 518 & 0'57 & 598 & 0'57 \\
\hline Martínez & 325 & 0'36 & 252 & 0'24 \\
\hline Diego Álvaro & 226 & 0'25 & 314 & 0'30 \\
\hline El Guijo & 193 & 0'21 & 237 & 0'23 \\
\hline Total & 2.271 & 2 2'49 & 2.376 & 2'26 \\
\hline
\end{tabular}

\subsection{Los oficiales de justicia}

En consonancia con los grados de jurisdicción contemplados en el organigrama jurídico castellano existían 2 tipos de oficiales de justicia: jueces ordinarios o locales que 
administraban justicia en primera instancia y jueces superiores o de apelación; a los que cabía añadir los pedáneos sin jurisdicción propiamente dicha (Sánchez-Arcilla, 2015).

\subsubsection{Jueces superiores}

Los oficiales superiores tienen un origen posterior a los ordinarios, y fueron una figura históricamente superpuesta, su razón de ser es la de atender las apelaciones de los oficiales ordinarios en representación del titular jurisdiccional. Sus orígenes están en la creación por la Corona de la figura del corregidor (Álvarez, 2012) y sus alcaldes mayores (Bernardo, 1978) que funcionaron como delegados regios interpuestos en las principales plazas urbanas para el control de los oficiales de justicia ordinarios, cuyo nombramiento había sido enajenado a la Corona, y con ello su control, y el de los concejos. Emulando al aparato realengo los señores implantaron figuras homólogas en funciones y designación —en su mayoría alcaldes mayores o corregidores, en menos casos gobernadores- A ellos tocaba el control de los ordinarios y sus residencias (Rubio, 1998); en ocasiones, la expedición de nombramientos por delegación del señor, o incluso funciones hacendísticas y gubernativo, que, aunque restringida por la legislación castellana ${ }^{9}$, ejerciéndolas aún en el siglo XVIII (Pousa, 2019).

Los corregidores de Ávila eran de capa y espada y contaban con un alcalde mayor, hasta 1773 en que pasan a ser de letras y se suprime la alcaldía (Martín, 1995: 147-148). La duración del cargo fue anual hasta la fijación de las intendencias, fecha en la que pasa a ser trienal, y a partir de 1783 sexenal-prorrogable por voluntad regia-. Su salario procedía de los propios y arbitrios de la ciudad, reduciéndose a 3.000 reales anuales con la creación de la intendencia, e incrementándose con la supresión de la alcaldía mayor. Dada la inexistencia de oficiales ordinarios en Ávila era tanto juez de primera instancia como de apelación. Le correspondía la presidencia no solo del concejo urbano, sino también de la Junta del Común y la de la Universidad de la Tierra (Ibáñez, 1986: 151-155).

En Ávila se han documentado alcaldes mayores en Oropesa, Calzada y Lagartera; 1 juez de apelaciones y alcaide de fortaleza en Villafranca de la Sierra; 1 alcalde mayor en Bercimuelle y otro en Navalcán ${ }^{10}$. De estos, algunos como los de Oropesa, Calzada de Oropesa, Bercimuelle y Navalcán poseían acumulativamente la jurisdicción en primera y segunda instancia.

\subsubsection{Alcaldes ordinarios}

Estos oficiales representan el número más elevado, en la totalidad de jurisdicciones documentadas en la provincia de Ávila a través de las Respuestas Generales del Catastro de Ensenada reciben la denominación de alcaldes, salvo en Mombeltrán, Ávila, Arévalo y Armenteros donde la jurisdicción ordinaria recaía acumulativamente en el oficial superior —rasgo diferencial con Galicia donde mayoritariamente se llamaban jueces—. Su número oscilaba entre 1 y 2 oficiales según la población en algunas. Estos cargos tenían una duración anual, en el caso de Ávila la fuente, a diferencia de Palencia, por ejemplo, no proporciona información acerca del sistema de elección, a menudo enajenada al titular de la jurisdicción por su concejo o las oligarquías y solo. Sin embargo, en algunos casos como Oropesa nos consta que tal enajenación no tuvo lugar y sus señores se reservaron la elección de justicia sin proposición ${ }^{11}$. Solo en Fontiveros y Fuente El Sol ${ }^{12}$ consta que su elección se hiciera por estados.

9 Castillo de Bobadilla, 1597.

10 AGS (Archivo General de Simancas), CE (Catastro de Ensenada), RG (Respuestas Generales), lib. 9, fol. 421.

11 AGS, CE, RG, lib. 6, fol. 468.

12 AGS, CE, RG, lib. 4, fols. 103 y f. 212. 
Tabla 6. Oficiales de justicia ordinaria (Of.) por jurisdicción en 1768

\begin{tabular}{|c|c|c|c|c|c|c|c|}
\hline Jurisdicción & Of. & Hab. & Hab/Of. & Jurisdicción & Of. & Hab. & Hab/Of. \\
\hline Navas del Marqués & 1 & 2.362 & 2.362 & Fontiveros & 2 & 503 & 226 \\
\hline Calzada Oropesa & 1 & 1.978 & 1.978 & Iglesuela & 2 & 514 & 257 \\
\hline Mombeltrán & 1 & 1.869 & 1.869 & Torralba & 1 & 254 & 254 \\
\hline Valdeverdeja & 1 & 1.815 & 1.815 & Navamorcuende & 2 & 521 & 235 \\
\hline Oropesa & 1 & 1.775 & 1.775 & Parrillas & 2 & 466 & 233 \\
\hline Lagartera & 1 & 1.453 & 1453 & Cisla & 1 & 224 & 224 \\
\hline Navalcán & 1 & 919 & 919 & Cruz de Pinares & 2 & 379 & 189 \\
\hline Pedro Bernardo & 2 & 1.823 & 911 & Fuentes del Año & 2 & 377 & 188 \\
\hline Candeleda & 2 & 1.579 & 789 & Vega & 2 & 370 & 185 \\
\hline Puente Congosto & 2 & 1.447 & 723 & Fuente el Sol & 1 & 184 & 184 \\
\hline Bonilla & 2 & 1.335 & 667 & Flores de Ávila & 2 & 364 & 182 \\
\hline Casavieja & 2 & 1.176 & 588 & Fresnedilla & 2 & 346 & 173 \\
\hline Piedralavés & 2 & 1.087 & 543 & Hoyo de Pinares & 2 & 347 & 173 \\
\hline Mijares & 2 & 916 & 459 & Navacepedilla & 2 & 327 & 163 \\
\hline Villatoro & 2 & 906 & 453 & Sotillo Palomas & 1 & 157 & 157 \\
\hline Bohonal & 2 & 887 & 443 & Herradón & 2 & 305 & 152 \\
\hline Adrada & 2 & 850 & 425 & Aldeanueva & 2 & 295 & 147 \\
\hline Tiemblo & 2 & 841 & 420 & Poveda & 1 & 146 & 146 \\
\hline Villan. Gómez & 2 & 808 & 404 & Collado Contrer. & 3 & 408 & 136 \\
\hline Adanero & 2 & 805 & 402 & Sto. Domingo & 2 & 271 & 135 \\
\hline Almendral & 1 & 398 & 398 & Lanzahita & 2 & 269 & 134 \\
\hline Cespedosa & 2 & 774 & 387 & Bodón & 2 & 263 & 131 \\
\hline Villafranca & 2 & 763 & 381 & Herreros & 2 & 262 & 131 \\
\hline San Bartolomé & 2 & 723 & 361 & Cardiel & 1 & 129 & 129 \\
\hline Sotillos Adrada & 2 & 720 & 360 & Pozanco & 1 & 127 & 127 \\
\hline Cuevas Valle & 2 & 655 & 327 & Valmaqueda & 1 & 113 & 113 \\
\hline Buenaventura & 1 & 324 & 324 & Pajarejos & 1 & 112 & 112 \\
\hline Bercimuelle & 1 & 319 & 319 & Mancera & 1 & 98 & 98 \\
\hline Puebla Naciados & 1 & 315 & 315 & Fuente Sauz & 2 & 190 & 95 \\
\hline Pascual Cobo & 1 & 292 & 292 & Almarza & 1 & 90 & 90 \\
\hline Talavera Vieja & 1 & 283 & 283 & Vita & 2 & 153 & 76 \\
\hline Cardeñosa & 2 & 559 & 279 & Rivilla & 2 & 130 & 65 \\
\hline Navalperal & 1 & 265 & 265 & Pelayos Presa & 1 & 53 & 53 \\
\hline Cepeda Mora & 1 & 249 & 249 & Canales & 2 & 98 & 49 \\
\hline Horcajo & 2 & 455 & 227 & Villadey & 2 & 78 & 39 \\
\hline
\end{tabular}


En Ávila se han contabilizado 124 oficiales de justicia ordinaria 10 realengo-conejiles y 114 señoriales, con una media de 735 habs./vara en 1768, cifra elevada frente a los 1018 de Segovia, pero menor que la soriana de 582. Las diferencias entre unas varas y otras van desde los 2.362 domiciliarios de Navas del Marqués donde solo existía un oficial, hasta los 39 de Villadey. La baja cifra de habitantes por vara, superada en muchos casos por las pedanías "rurales", obliga a reconsiderar la condición urbana de las "villas", consecuencia exclusiva de la posesión de jurisdicción y oficiales propios.

\subsubsection{Oficiales pedáneos}

En contrapartida, Ávila no contaba demasiadas pedanías, pues la jurisdiccionalización redujo a unas pocas las jurisdicciones con concejos rurales dependientes. El medio de elección de los alcaldes pedáneos era distinto de unos lugares a otros, lo habitual es que fuesen electos anualmente por los concejos y el título lo expidiese el oficial ordinario de la jurisdicción, sin embargo, y en Segovia, a finales de la Edad Media consta el control de los dos oficios era elegido por el concejo de la capital quedando la elección del otro y los regidores — de haberlos - al concejo rural; pero Asenjo-González ha documentado que con el paso de concejo abierto al cerrado en mucho núcleos rurales ya a finales de la Edad Media se emplearía un sistema de cooptación (Asenjo, 1986: 491). La jurisdicción de los pedáneos era una jurisdicción delegada por los ordinarios, restringida a las causas menores, en algunos concejos leoneses limitadas pecuniariamente a 200 o 500 maravedís (Rubio, 1998: 83) y en algunos castellanos, como Moncalvillo o Daroca a las causas de menos de 400 maravedís ${ }^{13}$.

\section{LOS CONCEJOS}

El otro poder en torno al que se estructuró la administración territorial castellana fue el municipal: rural y urbano. Su capacidad legislativa en materia económica y fiscal jugó un papel esencial e hizo de sus cargos un objeto deseado en la construcción de las redes de intereses locales; constituyéndose en peldaño para el ascenso social, y manifestación honorífica.

Jurisdicción y concejo no constituyeron poderes aislados. El concejo funcionaba como engarce entre el poder desde arriba y el pueblo y a su vez necesitaba de la superioridad en la que residía la jurisdicción, para investirse de autoridad institucional, tocando a esta la investidura de los oficiales concejiles. Por ello, y pese a la pugna de las comunidades para elegir a sus propias justicias y gobernantes y la patrimonialización de oficios concejiles, su nombramiento permaneció como una prerrogativa de la superioridad, ya fuera la Corona o un señor jurisdiccional.

El reinado de Alfonso XI ha sido visto como el eje a partir del cual los concejos castellanos en sus diversas formas abiertas avanzan hacia la que será su forma común en toda la Corona de Castilla, el regimiento cerrado con una planta más o menos compleja según los casos, con oficiales separados para cada función - jurisdiccional, gubernativa y sindical-, o por el contrario recayendo estas en el mismo individuo en el caso de concejos rurales modestos. Aunque esto no implicó la desaparición de las asambleas abiertas.

En el caso de Ávila como en Segovia, estos concejos rurales germinarán dentro de la antigua organización medieval de villa y tierra, que fue perdiendo funcionalidad ya desde la Baja Edad Media. El control que las capitales de las tierras ejercían sobre las poblaciones rurales (Martín, 1995: 161) las relegaba a un papel esencialmente fiscal supeditado (Monsalvo, 1990). De modo que la capital realizaba el reparto entre sus sexmos, y estos

13 AGS, CE, RG, lib. 59, fol. 412 y lib. 58, fol. 1. 
a su vez procedían al reparto entre pueblos. El crecimiento de estos núcleos rurales llevó a estos a la constitución de sus propios órganos de gobierno réplica de los urbanos —con sus justicias pedáneos, uno o dos regidores e incluso sus propios síndicos-. Llegado el XVIII además de los urbanos encontramos 186 concejos rurales, la mayoría en las antiguas tierras de Ávila, 116, y Arévalo, 52.

\subsection{La presidencia de los concejos: distinción entre concejos rurales y urbanos}

La presidencia de los concejos tocaba a los oficiales de justicia ordinaria, en los núcleos urbanos y a los pedáneos en el rural. Aunque en la Edad Media existieron figuras separadas de jueces y alcaldes —así consta en los fueros de Béjar, Plasencia, Soria— ${ }^{14}$, la primera figura sucumbe durante la Baja Edad Media en casi todos los concejos, a la pugna municipal por el control de estos oficios (Monsalvo, 2006: 70-176). Una excepción sería la propia Ávila, donde a principios del siglo XVI todavía documentamos jueces nombrados por la corona ${ }^{15}$. La enajenación de la designación del oficial de justicia tampoco triunfó en algunos señoríos, e incluso haciéndolo las decisiones de los ordinarios eran apelables ante los oficiales superiores. Y en los casos de señorialización tardía tales derechos fueron negociados y disputados por las villas con sus nuevos señores con distinto resultado (Lorenzo e Izquierdo, 2001).

La importancia de este fenómeno jurisdiccional concejil es que fue la causa que llevó a muchas poblaciones a erigirse en jurisdicciones independientes, aunque esto fue más típico del centro-norte del reino, que de su Extremadura, dando origen a un montón de villasjurisdicción de ínfimas dimensiones. En Ávila esta segregación se debió casi siempre a su paso a señorío. Constituyendo la disposición de justicias ordinarias la diferencia esencial entre núcleos "jurídicamente" urbanos y rurales.

\subsection{Regidores y síndicos}

Los regimientos abulenses tanto urbanos como rurales presentan una estructura sencilla, no se encuentran aquí estructuras complejas como las toledanas, con alféreces y alguaciles mayores con voz y voto — solo Ávila cuenta con un oficio de alférez mayor- ${ }^{16}$, asemejándose más a los concejos sencillos del centro del reino. La existencia de regidurías separadas de las pedanías en los rurales marca una diferencia esencial con los del norte, cántabros y gallegos. En especial estos donde no existieron regimientos rurales como tales y los pedáneos ejercieron simultáneamente las tres labores: judicial, gubernativa y representativa.

Los concejos de Ávila y Arévalo presentan un mayor número de oficios, pero reducido en comparación con otras capitales provinciales. La primera cifra de regidurías abulenses es del siglo XIII cuando cuantificamos 12 oficios de designación regia, y así permanecen hasta el siglo XV cuando ascienden a 14 (Cerda, 1987: 307-375; Moreno, 1985: 773-83). En origen, fueron de provisión regia, e incluso consta que los monarcas no esperaban a su vacación para reemplazar a sus titulares. Sin embargo, en el transcurso de estas dos centurias el afianzamiento de las oligarquías locales lleva a los monarcas a condescender en "las renuncias a favor de", tomando los titulares el control de los oficios de forma permanente para sus linajes (Monsalvo, 2019: 103-139; Martínez, 2014: 889-918; Diago, 1997: 143-177; Asenjo, 2009: 52-84; Moreno, 1992: 154 y 185).

Si las regidurías abulenses escaparon a los acrecentamientos de oficios por la venalidad en los siglos XVI y XVII (Tomás, 1999; Cuartas, 1983; Jiménez, 2012), no lo harían a las

14 Otros ejemplos: Sigüenza, Molina o San Esteban (Martínez Llorente, 1990: 442 y 445).

15 El 13 de agosto de 1518 se expide una de las últimas cédulas de nombramiento (Merino, 1926: 140).

16 AGS, CE, RG, lib. 1, fols. 67ss. 
reformas borbónicas (Guillamón, 2010). Así, a las regidurías perpetuas patrimonializadas vinieron a sumarse 6 regidurías trienales (Martín, 1995: 38), no fue una medida aislada, en el marco castellano, Cádiz también incorporaría varios regidores añales; y tampoco era esta una creación ex nuovo sino que nos remite a los orígenes de muchos concejos cuando los cargos todavía no habían sido patrimonializados (García, 1988) preservada en muchos casos.

Distinto fue el recorrido del regimiento de Arévalo y sus linajes hasta alcanzar las 11 regidurías que encontramos en el siglo XVIII ${ }^{17}$. Hasta el reinado de Juan II los linajes abulenses elegirían a sus regidores a sazón de dos por cada linaje. Juan II habría ordenado en 1431 la venta de las regidurías que vacaren en la villa, sin embargo, si se vendieron todos alguno o ninguno, la situación en que llegan al siglo XVI presupone un resultado mixto e idéntico al de Ávila. La provisión de regidores corresponde al monarca de entre los caballeros del linaje correspondiente bajo propuesta (Martínez, 1990: 898).

Los otros regimientos más amplios de la provincia serían los de Puente Congosto, con cuatro regidores, Mombeltrán, con cuatro, y Villafranca de la Sierra, con tres ${ }^{18}$. Frente a los casos de patrimonialización realengos, en estas villas de señorío la elección de regidores escapó al control del señor, que quedó restringida a la de los oficiales de justicia, escribanos de número y alguaciles. En estos casos las regidurías funcionaban como el resto de los oficios concejiles, como cargos anuales de elección popular, tanto en los concejos rurales como en los urbanos. En Mombeltrán la elección se practicaba por estados, dos regidores por el estado noble y dos por el llano ${ }^{19}$. Emulando a los urbanos casi todos los concejos rurales abulenses dispusieron de oficios de regidores separados de los pedáneos, con las excepciones en la jurisdicción de Arévalo de Blasconuño, Castellanos, Espinosa, Honcalada, Honquilana, Pedro Rodríguez, Cristóbal de Vega, San Esteban de Zapardiel, San Llorente, San Vicente de Arévalo y Vinaderos -y Constanza y Donjimeno donde coexistieron alcaldes de hermandad junto a los pedáneos_-; en la de Ávila: Aveinte, Balbarda, Berlanas, Bravos, Colilla, Crespos, Grajos, Ortigosa, .Gallegos, Hoyo Quesero, Marlín, Morañuela, Muñochas, Muñogrande, Muñomer, Naharros, Navalmoral, Oco, Salobral, Sanchicorto, San Pedro de Arroyo, Viñegra; y en Bonilla de la Sierra los concejos aparecían constituidos entorno al procurador sexmero y los pedáneos.

Del $81 \%$ de los concejos rurales abulenses que contaban con figura separada para los regidores, menos de 69 contaron además con síndicos, pues eran varios los regidores que aunaban ambas funciones. Esto representaba al 37\% de los concejos rurales de la provincia, los que dispusieron de plantas concejiles complejas.

\section{CONCLUSIONES}

La Corona de Castilla presentó un grado de parcelación jurisdiccional intermedio, alejado del reino de León o del de Galicia, y con profundas diferencias regionales, acuciadas entre la Extremadura castellana y la zona centro-norte. Esto se debió a la sujeción del sistema de villa y tierra de muchas poblaciones que evitó su consolidación como villas y jurisdicciones independientes.

Sin embargo, el volumen de vasallos señoriales superaba a los de realengo con mayor diferencia que en el norte. En el proceso de señorialización extremeño pueden distinguirse 3 etapas: $1^{\mathrm{a}}$ ) entre el reinado de Alfonso VI y Pedro I; $2^{\mathrm{a}}$ ) Trastámara y $3^{\mathrm{a}}$ ) Habsburgo. La Trastámara supuso una mayor pérdida en territorios y vasallos, mientras la Habsburgo

17 AGS, CE, RG, lib. 1, fols. 147.

18 AGS, CE, RG, lib. 9, fol. 421.

19 AGS, CE, RG, lib. 5, 347-349. 
multiplicaría la juridification. Estas ventas sirvieron a varias poblaciones para conseguir la deseada autonomía concejil, rasgo común con Asturias, solo que en aquellas el fenómeno se debió a las desamortizaciones de Felipe II y en Ávila fueron las ventas de Felipe III y IV las que tuvieron mayores efectos. En este proceso las comunidades de villa y tierra y el poder cuasi propio de un señorío concejil alcanzado por sus capitales jugaron un papel fundamental en la preservación de las amplias jurisdicciones realengas de Ávila y Arévalo.

En cuanto a los concejos el trabajo ha puesto de relieve la proliferación que estos tuvieron no solo en el ámbito urbano, regulados desde sus primeros tiempos por la monarquía, sino también en las poblaciones rurales, que encontraron en la organización concejil una vía de autogestión e independencia que no había lugar en los esquemas de villa y tierra; emulando las plantas concejiles urbanas. Estos gozaron de una cota de autonomía mayor, por cuanto los señores no se intrusaron en el control de sus oficios. Ante este panorama administrativo, la cuestión en torno a la urbanidad de las "villas", frente a los" lugares" de la Extremadura Castellana manifiesta que, esta, vino determinada únicamente por su eventual erección en jurisdicciones independientes ${ }^{20}$.

\section{BIBLIOGRAFÍA}

Abad Martín, Á. S., (1995), "Los señoríos en la montaña palentina: el marquesado de Aguilar", Actas del III Congreso de Historia de Palencia, Palencia, Diputación Provincial de Palencia, pp. 527-550.

Álvarez Cañas, M. L. (2012), Corregidores y alcaldes mayores: la administración territorial andaluza en el siglo XVIII, Alicante, Universidad de Alicante.

Álvarez Villar, J. (1972), La villa condal de Miranda del Castañar, Salamanca, Centro de Estudios Salamantino.

Asenjo González, M. (2009), "Acerca de los linajes urbanos y su conflictividad en las ciudades castellanas a fines de la Edad Media", Clío \& Crimen, 6, pp. 52-84.

- (2005), "Función pacificadora y judicial de los corregidores en las villas y ciudades castellanas, a fines de la Edad Media", Medievalista, 18.

Ávila Seoane, N. (2005), El proceso de señorialización de la Extremadura castellana (siglos XII-XVIII), Madrid, Universidad Complutense de Madrid.

- (2003), "El proceso de señorialización del concejo de Arévalo en los siglos XIV y XV", En la España Medieval, 26, pp. 97-126.

Barrios García, Á. (1983), Estructuras agrarias y de poder en Castilla: el ejemplo de Ávila (1085-1320), Salamanca, Universidad de Salamanca.

- (1981), Documentación medieval de la catedral de Ávila, Salamanca, Universidad de Salamanca.

- (1973), La catedral de Ávila en la Edad Media. Estructura sociojurídica y económica, Ávila, Caja Central de Ahorros y Préstamos.

Bermúdez Aznar, A. (1972), El corregidor en Castilla durante la Baja Edad Media, Madrid, Universidad Complutense de Madrid.

Bernardo Ares, J. M. (1996), "El régimen municipal en la Corona de Castilla”, Studia Histórica. Historia Moderna, 15, pp. 23-71.

- (1978), Los alcaldes mayores de Córdoba, Córdoba, Imp. San Pablo.

Calderón Ortega, J. M. y Alonso Campos, J. I. (1990), "El señorío de Villaviudas", Actas del II Congreso de Historia de Palencia, Palencia, Diputación Provincial de Palencia, II, pp. 557-567.

Camarero Bullón, C. (2002), "El catastro de Ensenada, 1749-1759: diez años de intenso

20 Monsalvo ya había señalado que tal designación no procedía sino de la réplica del sistema organizativo territorial existente, en el que los entes autónomos dotados de gobierno se intitulaban villas (1998: 275-338). 
trabajo y 80.000 volúmenes manuscritos", CT, Catastro, 46, 61-88.

Camarero Bullón, C. Domínguez Ortiz, A. y Campos, J. (1991), Vecindario de Ensenada, 1759, Madrid, Tabapress.

Carriazo Rubio, J. L. (2013), "La genealogía de los señores de la casa de Medina Sidonia de Luis de Salazar y Castro", Historia y Genealogía, 3, pp. 41-64.

Cerda Ruiz Funes, J. (1987), "Hombres buenos, jurados y regidores en los municipios castellanos de la Baja Edad Media", Estudios sobre instituciones jurídicas medievales de Murcia y su reino, Murcia, pp. 307-375.

Colombo, O. (2019), "Oligarquías concejiles y prácticas señorializadoras en el territorio de Ávila a fines de la Edad Media", Edad Media, 20, pp. 215-243.

Corada Alonso, A. (2015), "Hacienda, rentas y privilegios de los marqueses de Aguilar de Campoo. Una aproximación desde el Catastro de Ensenada", Estudios Humanísticos, 13, pp. 61-95.

Crubaugh, A. (2001), Balancing the scales of justice. Local courts and rural society in southwest France, 1750-1800, Pennsylvania State University Press.

Diago Hernando, M. (1997), "El papel de los linajes en las estructuras de gobierno urbano de Castilla y en el imperio alemán durante los siglos Bajomedievales", En La España Medieval, 20, pp. 143-177.

Domínguez Ortiz, A. (1974), El régimen señorial y el reformismo borbónico, Madrid, Real Academia de la Historia.

- (1964), "Ventas y exenciones de lugares durante el reinado de Felipe IV", Anuario de Historia del Derecho Español, 34, pp. 163-207.

Eiras Roel, A. (1989), "El señorío gallego en cifras. Nómina y ranking de los señores jurisdiccionales gallegos", Cuadernos de Estudios Gallegos, 38, pp. 113-135.

Faya Díaz, M. Á. (1998), “La venta de señoríos eclesiásticos de Castilla y León en el siglo XVI", Hispania, 58, pp. 1045-1096.

Fernández Martín, L. (1977), "El marquesado de Frechilla y Villarramiel prenda de la unión peninsular", Archivos Leoneses, 61, pp. 9-56.

Fortea Pérez, J. I. (2012), "Los corregidores de Castilla bajo los Austrias (1588-1633)", Studia Histórica. Historia Moderna, 34, pp. 99-146.

Francisco Olmos, J. M. (1999), Los miembros del Consejo de Hacienda en el siglo XVII, Madrid, Castellum,

Franco Silva, A. (2015), "Notas sobre las alcaidías de las fortalezas de los duques de Alburquerque. Cuéllar, Buengrado, Ledesma y Huelma", Estudios en homenaje al profesor César González Mínguez, Bilbao, Universidad del País Vasco, pp. 83-110.

- (2012), "Jurisdicción y conflicto. Las confiscaciones de señoríos en la época de los Trastámara", Historia de la propiedad. La expropiación, Salamanca, Universidad de Salamanca, pp. 13-50.

- (2007), Señoríos y ordenanzas. Villafranca de la Sierra y las Navas, 2007.

- (1990), "La fundación de pueblas en tierras situadas al noroeste del reino de Toledo a fines del siglo XIII", Historia. Instituciones. Documentos, 17, pp. 31-53.

- (1985), "Oropesa, el nacimiento de un señorío toledano del siglo XIV", Hispania, 68, pp. 299-314.

García Baquero, A. (1988), "Un aspecto olvidado del reformismo municipal carolino, la reinstauración de las regidurías añales en Cádiz", Carlos III y la Ilustración, Madrid, Ministerio de Cultura, I, pp. 387-404.

García de Cortázar, J. Á. (1985), Organización social del espacio en la España Medieval. La Corona de Castilla en los siglos VIII al XV, Barcelona, Ariel.

Garrigós Pico, E. (1982), "Organización territorial de España a fines del Antiguo Régimen", 
La economía española a fines del Antiguo Régimen, Madrid, Alianza, pp. 3-105.

Gil Crespo, A. (1986), "La desamortización eclesiástica en la provincia de Ávila”, Cuadernos Abulenses, 5, pp. 91-112.

Gómez Izquierdo, A. (2000), Introducción a la historia de Zapardiel de la Cañada, pp. 80-81. González Alonso, B. (1970), El corregidor castellano (1348-1808), Madrid, Instituto de Estudios Administrativos.

González Vázquez, S. (2006), La señorialización de la tierra de Ávila (siglo XII-XV): Aportación al estudio de los señoríos en la zona de Castilla, Burgos, Universidad de Burgos, 2006.

Gonzalo Muñoz, J. M. (1994), "El marquesado de La Adrada", Cuadernos Abulenses, 21, pp. 177-192.

Grasotti, H. (1983), "Hacia las concesiones de señorío con mero misto imperio", en Estudios en Homenaje al prof. Claudio Sánchez Albornoz, Madrid, Instituto de España, pp. 113150.

- (1967), "Un abulense en Beaucaire", Cuadernos de Historia de España, 44, pp. 134135.

Guglielmi, N. (1953), "El dominus villae en Castilla y León", Cuadernos de Historia de España, 19, pp. 55-103.

Guilarte, A. M. (1987), El régimen señorial en el siglo XVI, Valladolid, Universidad de Valladolid.

Guio Castaños, G. y Guio Martín, J. (2007), El palacio de Contreras y la academia de intendencia de Ávila, Madrid, Fundación Sánchez Albornoz.

Heras Santos, J. (1996), "La organización de la justicia real ordinaria en la Corona de Castilla durante la Edad Moderna", Studis, 22, pp. 105-140.

Guillamón Álvarez, J. (2010), Reformismo en los límites del orden estamental: de Saavedra Fajardo a Floridablanca, Murcia, Universidad de Murcia.

Ibáñez Molina, M. (1986), "Una visión retrospectiva sobre las intendencias de 1718", Cuadernos de Investigación Histórica, 10, pp. 153-164.

Iradiel Murugarren, P. (1997), Señoríos jurisdiccionales y poderes públicos a finales de la Edad Media, Madrid, Departamento de Educación y Cultura.

Lemeunier, G. (1998), Los señoríos murcianos. Siglos XVI-XVII. Murcia, Universidad de Murcia.

López-Guadalupe Pallarés, M. J. (2018), "Procesos de señorialización en los concejos de realengo de la Extremadura castellano-leonesa. Un estado de la cuestión", Espacio, Tiempo y Forma. Historia Medieval, 31, pp. 431-454.

Lorenzo Pinar, F. J. e Izquierdo Misiego, J. I. (2001), "Ventas jurisdiccionales abulenses en tiempos de Felipe III y Felipe IV", Studia Historica. Historia Moderna, 23, pp. 199-231.

Luis López, C. (2013), "Los titulares del señorío de Villafranca de la Sierra, desde su creación hasta su unión con el de las Navas después del llamado pleito de Villafranca (12561389)", El Historiador y la Sociedad, Salamanca, Universidad de Salamanca.

Martín García, G. (1995), El ayuntamiento de Ávila en el siglo XVIII, Ávila, Diputación Provincial de Ávila.

Martín Ramírez, J. A. (1997), Los Dávila, señores de Villafranca y las Navas en la Baja Edad Media, Tesis doctoral, Universidad de Cádiz.

Martínez Casado, A. (1994), Lope de Barrientos, un intelectual en la corte de Juan II, Salamanca, San Esteban.

Martínez Díez, G. (1983), Las comunidades de Villa y Tierra de la Extremadura Castellana, Madrid (2017), Máxtor.

Martínez Llorente, F. (2014), “Las Juntas de nobles linajes de Ávila y Arévalo. Aportación 
al estudio de la funcionalidad política de unas corporaciones nobiliarias de ámbito concejil (siglos XIII-XIX)", Historias Iuris estudios dedicados al profesor Santos M. Coronas González, 2, pp. 889-918.

- (2002), "Hacia la nobleza titulada: el linaje Montalvo de Arévalo y su señorío sobre Botalhorno (siglos XIV-XV)", Cuadernos Abulenses, 31, pp. 197-206.

- (1990), Régimen jurídico de la Extremadura castellana medieval, Valladolid, Universidad de Valladolid.

Mauclair, F. (2001), "La justice dans les campagnes françaises à la fin de l'Ancient Régime : un nouveau regard sur les tribunaux seigneuriaux du XVIIIe siècle", Justice et sociétés rurales du XVI siècle á nos jours, Rennes, Presses Universitaires de Rennes.

Merino Álvarez, A. (1926), La sociedad abulense durante el siglo XVI. La nobleza, Madrid, Imprenta del patronato de Huérfanos.

Mitre Fernández, E. (1969), La extensión del régimen de corregidores en el reinado de Enrique III de Castilla, Valladolid, Universidad de Valladolid.

- (1968), La evolución de la nobleza en Castila bajo Enrique III (1396-1406), Valladolid, Universidad de Valladolid.

Monsalvo Antón, J. M. (2019), "El papel político de los linajes urbanos en los concejos al sur del Duero", Élites, conflictos y discursos políticos en las ciudades bajomedievales de la península ibérica, Salamanca, Universidad de Salamanca, pp. 103-139.

- (2006), "El realengo y sus estructuras de poder durante la Baja Edad Media", Historia de Ávila, Ávila, Institución Gran Duque de Alba, III, pp. 70-172.

- (1999), "Los territorios de las villas reales de la vieja Castilla, ss. XI-XIV: Antecedentes, génesis y evolución", Studia Historica. Historia Medieval, 17, pp. 15-86.

- (1998), "Las dos escalas de la señorialización nobiliaria al sur del Duero", Les senyories medievals. Una visió sobre les formes del poder feudal, Revista d'Historia Medieval, 8, pp. 275-338.

- (1990), Ordenanzas de Ávila y su tierra, Ávila, Institución Gran Duque de Alba.

Montalvo, J. J. (1928), De la historia de Arévalo y sus sexmos, Ávila, 1928.

Montgomery, C. (2004), "Prohibitions to protect one non-common law court against another", The writ of prohibition: jurisdiction in Early Modern English Law, Chicago, D’Angelo Law Library Publications, 3, pp. 155-169.

Moreno Núñez, J. I. (1992), Ávila y su tierra en la Baja Edad Media (siglos XIII-XV), Ávila, Junta de Castilla y León.

- (1985), "El concejo de Toro en el siglo XV", Coloquio sobre la ciudad hispánica durante los siglos XIII y XVI, Madrid, pp. 773-83.

Moxó Ortiz de Villajos, S. (1973), Los antiguos señoríos de Toledo, Toledo, Universidad Complutense.

- (1964), "Los señoríos. En torno a una problemática para su estudio", Hispania, 24, pp. 399-430.

Outwite, R. (2007), The rise and fall of the English ecclesiastical courts, 1500-1860, Cambridge, Cambridge University Press.

Palencia Herrejón, J. R. (1995), "Fundación y consolidación del marquesado de Aguilar a través de los pleitos de Garci Fernández Manrique", Actas del III Congreso de Historia de Palencia, Palencia, Diputación Provincial de Palencia, pp. 787-794.

Patterson, C. (1999), "Corporations and competing authorities", Urban patronage in early modern England, Stanford, Stanford University Press, pp. 120-152.

Polo Martín, R. (2012), "Las ordenanzas de un lugar de señorío: Cepeda", Anuario de Historia del Derecho Español, 82, pp. 763-781.

Pousa Diéguez, R. (2020), "La administración de justicia ordinaria en la Corona de Castilla: 
la división jurisdiccional de Soria en la segunda mitad del siglo XVIII", Cuadernos de Historia Moderna, 45 (en prensa).

- (2019), Señoríos costeros y villas portuarias en la Galicia del siglo XVIII, Vigo, Universidad de Vigo.

- (2018), "Del señorío medieval a la jurisdicción señorial en Galicia", Medievalismo, 28, pp. 175-202.

Reviejo Paz, J. A. (2013), "El señorío de Villafranca de la Sierra: una concesión temprana", Espacio, Tiempo y Forma. Historia Medieval, 26, pp. 319-364.

Rubio Pérez, L. (1998), Visitas, juicios de residencia y poder concejil en la provincia de León, León, Universidad de León.

Salazar y Castro, L. (1688), Advertencias históricas sobre las obras de algunos doctos escritores modernos, Madrid, Matheo Llanos y Guzmán.

Sánchez-Arcilla, J. (2015), La administración de justicia real en Castilla y León en la Baja Edad Media, Madrid, Universidad Complutense de Madrid, pp. 693-825.

Soler Navarro, A. (2009), El ducado de Peñaranda: su origen y desarrollo hasta la desaparición del linaje de los Zúñiga, Universidad Complutense de Madrid.

Suárez Fernández, L. (1966), "Castilla, 1350-1406", Historia de España, Madrid, Espasa Calpe, XIV, pp. 1-378.

Tomás y Valiente, F. (1999), "Ventas de oficios públicos en Castilla durante los siglos XVII y XVIII", Gobierno e instituciones en la España del Antiguo Régimen. Madrid, Alianza, pp. 151-177.

Tellería Orbelzu, A. (2001), "El señorío de Villafranca de la Sierra en Ávila: dos diplomas medievales en el archivo de la Real Chancillería de Valladolid", pp. 227-232.

Valdeón Baruque, J. (1968), "Notas sobre las mercedes de Enrique II", Hispania, 28, pp. 38-55.

Vermeesch, G. (2015), "Reflections on the relative accessibility of law courts in early modern Europe", Crime, Histoire et Sociétés, 19, pp. 53-76. 